\title{
Prevalence of obesity among school-age children and adolescents in the Gulf cooperation council (GCC) states: a systematic review
}

Hanouf Al Hammadi and John Reilly

\begin{abstract}
Background: The Gulf Cooperation Council (GCC) countries have among the highest prevalence of adult obesity and type 2 diabetes in the world. This study aimed to estimate the recent prevalence of obesity among school-age children and adolescents in the GCC States.

Methods: The literature search for obesity prevalence data was carried out in July 2017 in Google Scholar, Physical education index, Medline, SCOPUS, WHO, 2007-2017, and updated in November 2018.In addition, 22 experts from the GCC were contacted to check the search results, and to suggest studies or grey literature which had been missed. Eligible studies were assessed for quality by using the Joanna Briggs Institute (JBI) tool for prevalence studies. Conduct of the systematic review followed the Assessment of Multiple Systematic Reviews Tool (AMSTAR) guidance. A narrative synthesis was conducted.

Results: Out of 392 studies identified, 41 full-text reports were screened for eligibility; 11 of which were eligible and so were included, from 3 of the 6 GCC countries (United Arab Emirates, Kuwait, Saudi Arabia). Surveillance seems good in Kuwait in compared to other countries, with one recent national survey of prevalence. Quality of the eligible studies was generally low-moderate according to the JNBI tool: representative samples were rare; participation rates low; power calculations were mentioned by only $3 / 11$ studies and confidence intervals around prevalence estimates provided by only $3 / 11$ eligible studies; none of the studies acknowledged that prevalence estimates were conservative (being based on BMl-for-age). There was generally a very high prevalence of obesity (at least one quarter-one third of study or survey participants obese according to BMI-for-age), prevalence increased with age, and was consistently higher in boys than girls.
\end{abstract}

Conclusions: The prevalence of obesity among school-age children and adolescents appears to have reached alarming levels in the GCC, but there are a number of major gaps and limitations in obesity surveillance in the GCC states. More national surveys of child and adolescent obesity prevalence are required for the GCC states.

Trial registration: PROSPERO registration number CRD42017073692.

Keywords: Children, Adolescents, Obesity, Body mass index, Systematic review, Gulf cooperation council (GCC)

\footnotetext{
* Correspondence: john.j.reilly@strath.ac.uk

University of Strathclyde, Physical Activity for Health Group, Glasgow G1 1XQ

Scotland
}

(C) The Author(s). 2019 Open Access This article is distributed under the terms of the Creative Commons Attribution 4.0 International License (http://creativecommons.org/licenses/by/4.0/), which permits unrestricted use, distribution, and reproduction in any medium, provided you give appropriate credit to the original author(s) and the source, provide a link to the Creative Commons license, and indicate if changes were made. The Creative Commons Public Domain Dedication waiver (http://creativecommons.org/publicdomain/zero/1.0/) applies to the data made available in this article, unless otherwise stated. 


\section{Background}

The Gulf Cooperation council countries include Kuwait, the United Arab Emirates (UAE), Qatar, Bahrain, the Kingdom of Saudi Arabia (KSA), and Oman. The GCC countries have among the highest adult obesity and type 2 diabetes prevalence in the world [1-4] with rapidly increasing prevalence of adult obesity and diabetes in the past two decades [1]. Several factors have contributed to the high prevalence of obesity in the GCC countries [2], notably the very large and rapid increases in household income, with associated lifestyle changes that include reduced physical activity and increased consumption of obesogenic foods and drinks [5, 6].

Surveillance of childhood obesity is considered central to tackling the obesity epidemic [7], but there may be a number of important limitations in surveillance of child and adolescent obesity prevalence in the GCC at present. Specifically, we were unable to find a recent systematic review of obesity prevalence of children and adolescents in the GCC, so prevalence of the problem is unclear. Our initial scoping review also suggested that many previous studies combined the prevalence of overweight and obesity, and so the prevalence of obesity could not be determined. In addition, many previous studies in the GCC collected data over 10 years ago and these studies may now be out of date given the rapid increases in prevalence in the region $[8,9]$. The recently published global estimates of obesity prevalence $[10,11]$ used data from the GCC countries which were also over 10 years old for example, so there is a need for prevalence data from more recent studies and surveys. An additional problem with older evidence is the fact that definitions of child and adolescent obesity have evolved over the past decade. Specifically, the WHO definition of child and adolescent obesity based on BMI-for-age was not published until 2007, and was not in widespread use until some time after that. A further problem with existing obesity prevalence data is that systematic reviews demonstrating limitations of BMI-for-age as a surveillance tool (high specificity for excessive fatness, but only low-moderate sensitivity) have become available only relatively recently $[12,13]$ and recent obesity prevalence studies or surveys from the GCC countries may not have made allowances for this important source of bias in prevalence estimates.

The primary aim of the present study was therefore to establish the recent (last 11 years) prevalence of obesity among school-age children and adolescents in the GCC states. Secondary aims were: to identify differences in prevalence between countries and between groups (e.g. by gender, age); to identify major gaps and weaknesses in the evidence base on obesity prevalence in the GCC. The study was intended to help improve child and adolescent obesity surveillance in the GCC in future, so that public health action aimed at tackling the obesity epidemic in the GCC can be better informed [7].

\section{Methods}

Registration and reporting of the systematic review

This systematic literature review was reported in accordance with the Preferred Reporting Items for Systematic Reviews (PRISMA) guidelines [14]. The review protocol was registered on PROSPERO on the 10th September 2017 (registration number CRD42017073692), the international prospective register for systematic reviews (https://www.crd.york.ac.uk/prospero/display_re cord.php?RecordID=73692). The search strategy followed the PECO (population, exposure, comparator and outcome) format: population = school-age children and adolescents in the GCC countries; exposure=obesity as defined using BMI-for-age; comparator = any appropriate BMI-for-age reference data; outcome = prevalence of obesity among the general population since 2007 .

\section{Literature search}

The literature search was originally conducted on 17 July 2017. The manuscript was submitted to this journal on 28th February 2018 and reviews were not received until October 2018, so the original searches were repeated on 2nd November 2018. Searches used the five most relevant electronic databases: Medline, Google Scholar, Physical education Index, SCOPUS and WHO. The search terms used in Medline are provided in Additional file 1: Table S1, as required by the PRISMA checklist; terms were very similar in the other databases, though with small differences in syntax between databases. The electronic database searching was complemented by reference citation tracking (forward and backward) of the included studies and of previous reviews, consultation with GCC-based experts in the field, and a search for 'grey literature' among the GCC experts (summarised in Additional file 2: Table S2).

\section{Study selection \\ Inclusion criteria}

Studies were included if they satisfied all of the following inclusion criteria: Prevalence data were collected in the last 11 years, i.e. from Jan 2007 to end October 2018; from a GCC country (Bahrain, Kuwait, Qatar, Oman, KSA, UAE); they provided prevalence of obesity rather than overweight prevalence, or prevalence of overweight/obesity combined; they must have defined obesity using an accepted method for children and adolescents based on BMI-for-age; BMI must have been based on measured height and weight (rather than self-report or parental report); age of study participants between 5 and 19 years; study participants from the general population (e.g. not from clinical samples).

\section{Exclusion criteria}

Studies were excluded if they addressed prevalence of obesity in middle Eastern countries that are not 
members of the GCC, with study participants outside the range 5-19; if prevalence data were collected earlier than 2007; if prevalence estimates from BMI-for-age were based on self-reported height or weight, or which combined prevalence of obesity and overweight so that obesity prevalence could not be ascertained. Studies that sampled from specific populations (e.g. clinical populations) were also excluded.

All literature search hits, and all potentially eligible studies identified by forward and backward citation searching, were examined for eligibility independently by both authors. The two authors resolved differences of opinion over eligibility by discussion, and in a few cases, by asking for clarification of methods from the authors of the original studies (e.g. over the precise data collection period where this was unclear in a few cases). A list of studies excluded at the full-text screening stage, with reason(s) for exclusion is providing in the supplementary material (Additional file 3: Table S3).

\section{Data extraction}

A data extraction form was devised in advance of the process of data extraction and used to populate the evidence tables given in the Results section below, with summary data on prevalence of obesity (with 95\% CI where possible) overall, and by subgroup as reported (e.g. by age, gender, definition of obesity). Both authors independently populated the data extraction forms, and they resolved any differences of opinion by discussion.

\section{Quality assessment-appraisal of eligible studies}

The quality of individual eligible studies was assessed by both authors independently using the Joanna Briggs Institute (JBI) checklist for assessment of the quality of prevalence studies [15]. Two additional aspects of prevalence study quality which are specific to obesity were also considered and added to the data extraction forms: the timing of data collection-given recent rapid increases in obesity prevalence in the GCC; $[8,9]$; whether biases arising from use of the BMI-for-age to estimate obesity prevalence $[12,13]$ had been considered by the authors (e.g. reported in the Discussion and/or used to adjust prevalence estimates in the Results).

\section{Guidance on maintaining the quality of the systematic review}

In an attempt to ensure high quality of the present review process the authors planned and conducted the review by addressing each of the items in the Assessment of multiple systematic reviews tool (AMSTAR [16]) checklist -the process is summarised in Table 1.

\section{Synthesis of study findings}

A meta-analysis of review findings was considered desirable if practical, but it was recognised that marked gaps in the evidence and /or differences between studies, e.g. differences in age or sex, ethnicity or socio-economic status of the samples, differences in time period [17], differences arising from differences in the definition of obesity used -which would be expected to be marked [12]-might preclude meta-analysis. Publication bias assessment was also considered desirable if possible.

\section{Results}

\section{Eligible studies and study selection process}

The PRISMA flow diagram is provided in Fig. 1. In the original search twenty-two potentially eligible papers were identified for full-text eligibility screening by both authors by the conventional literature searching and a further 17 papers/surveys from the grey literature were suggested by expert contacts in the GCC and all of those were full-text screened by both authors. The search update in November 2018 identified further studies for full-text screening but no additional eligible studies, so only 11 eligible papers/survey reports were identified, reporting 13 separate prevalence estimates, from 3 of the 6 GCC countries (UAE, Kuwait, KSA): there were no eligible studies from Oman, Bahrain, and Qatar. In summary, the number of eligible studies in the GCC countries was limited and the studies/surveys themselves differed substantially by time, sample age and sex, ethnicity, and by definitions of obesity used. No formal assessment of publication bias was possible given the small number of eligible studies, and so a narrative synthesis, by nation, is provided below.

\section{Study quality appraisal}

The formal appraisal of study quality for the 11 eligible studies/surveys is summarised in Table 2. A number of the quality assessment items were not reported or not carried out, in particular the use of nationally representative samples was rare (1/11 eligible studies), and few studies reported power calculations or confidence intervals for their prevalence estimates (only $3 / 11$ provided confidence intervals). In addition, few of the eligible studies/surveys were recent: 9 out of 11 studies collected data over 7 years ago. Finally, consideration of biases arising from use of BMI-for-age was not carried out (0/11 eligible studies referred to this major source of bias).

\section{Narrative synthesis by GCC nation \\ UAE}

Table 3 summarises the three eligible studies from the UAE [18-20]. None of the three studies used representative samples, though one study [18] was very large $(n=44,942)$, relatively recent (data collection 2013-2015), included both 
Table 1 AMSTAR Self-assessment of the process used in the present study

\begin{tabular}{|c|c|c|}
\hline Questions & $\begin{array}{l}\text { Yes/ } \\
\text { NO }\end{array}$ & Answers in detail \\
\hline 1) Did we have a PICO/PECO & Yes & $\begin{array}{l}\text { Population = children and adolescents of school-age as defined by WHO } \\
\text { (5-19yrs) from GCC countries; E = exposure = obesity defined using an } \\
\text { acceptable method based on BMI-for-age; Comparator = any appropriate } \\
\text { reference data; Outcome = prevalence of obesity rather than overweight } \\
\text { and not overweight/obesity combined, from } 2007 \text { onwards. }\end{array}$ \\
\hline $\begin{array}{l}\text { 2) Did we specify review methods in advance of doing } \\
\text { the review? }\end{array}$ & Yes & Registered in PROSPERO ref. CRD42017073692 \\
\hline $\begin{array}{l}\text { 3) Did we explain/justify inclusion criteria (based on } \\
\text { study design)? }\end{array}$ & Yes & $\begin{array}{l}\text { We did not exclude any study design, but RCT not likely to be that } \\
\text { relevant (though RCT could contain relevant data and so not excluded) }\end{array}$ \\
\hline \multirow[t]{3}{*}{ 4) Did we have a comprehensive lit search strategy? } & Yes & Electronic databases from 2007 to 2018: See Methods and Additional file 1. \\
\hline & & $\begin{array}{l}\text { We were resourced to search for English language publications only, } \\
\text { though literature suggested by expert contacts in the GCC (including } \\
\text { grey literature) in Arabic would have been considered eligible. }\end{array}$ \\
\hline & & $\begin{array}{l}\text { Searched reference lists of eligible studies? Yes, both forward and } \\
\text { backwards citation searching was carried out. }\end{array}$ \\
\hline
\end{tabular}

Consulted experts? Yes-list of $n=22$ expert contacts in all GCC countries was consulted in October-November 2017.The experts from the GCC were asked to check on the results of the literature search and if they were aware of any grey literature which was relevant (e.g. national surveys)

Search within 24 month of planning the search - Yes, within 2 months

5) Did review authors agree on inclusions/exclusions of full text potentially eligible studies?

6) Data extraction from eligible studies- did both review authors do this/check this?

7) Is a list of all excluded studies provided, including the reasons for exclusion?

8) Does the data extraction and narrative (Evidence tables and text) provide enough detail about the eligible studies?

9) Did the review authors consider risk of bias?

10) Did the review authors report sources of funding of their review?

11. \& 12 Did the review authors do a meta-analysis? (Was this appropriate?)

13) Did the review authors consider sources of bias in eligible studies?

14) Did review authors consider sources of heterogeneity in eligible studies?

15) Did review authors consider other sources of bias (in particular publication bias)

16) Did review authors consider any conflicts of interest which arose when doing their review?
Yes Both authors agreed on inclusions/exclusions of the full text articles screened

Yes Both authors agreed on data extraction from the eligible studies

Yes Appendix of excluded studies and reasons for exclusion is provided (Additional file 3).

Yes Text summarises the eligible studies, and details of eligible studies are provided in Evidence Tables (Results section)

Yes Results section (Evidence Tables) contains data on possible sources of bias including: sample size; representativeness of sample; bias arising from definition of obesity used.

Yes Kuwait Cultural Office and Scottish Funding Council

No No meta-analysis possible dues to degree of differences in study design and methods: different nations; differences in factors which create differences in prevalence estimates- different definitions of obesity, different age groups, different sex distributions in studies

Yes As above- the evidence tables deal with representativeness, sample size/power calculations, and biases in the definitions of obesity used by the studies

Yes Different times, different obesity definitions, different ages and sexes, different countries and places all considered

N/A No formal testing for publication bias was possible due to small number of eligible studies.

Main sources of bias in prevalence studies were considered: sample size and representativeness; use of BMl to estimate obesity prevalence is biased (underestimates obesity prevalence) as noted in the manuscript.

Yes No conflicts to declare nationals and non-nationals, and included a wide age range (3-18 years). In this study [18] by prevalence of obesity according to the WHO definition exceeded one third of the sample in the secondary school-age participants, and there was clear evidence of increasing prevalence with increasing age. The highest prevalence was recorded for age 11-14 years. In two of the three studies from the UAE $[19,20]$ obesity prevalence estimates were provided using more than one definition of obesity, and in both cases prevalence was substantially 


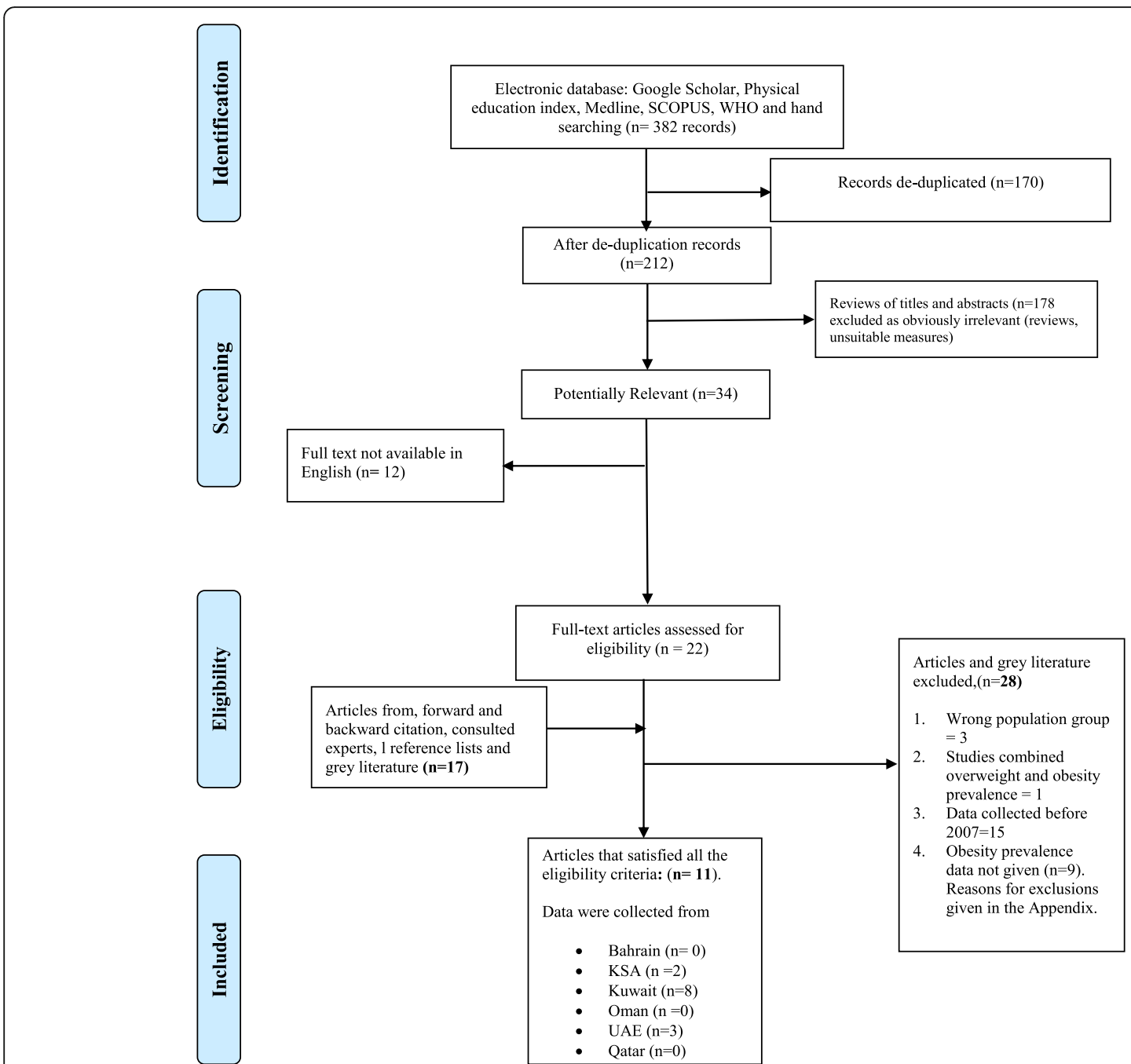

Fig. 1 PRISMA Study Flow Diagram. Footnote: search updates in November 2018 identified 10 additional potentially eligible studies, of which 6 were excluded from Abstract screening and four were deemed ineligible after full-text screening (see Additional file 3 )

lower using the International Obesity Task Force (IOTF) compared to the alternative definitions (from the US Centers for Disease Control and WHO respectively). In the one study which considered differences in obesity prevalence between the sexes, prevalence was much lower among girls than boys [19] .

\section{KSA}

Table 4 summarises the evidence from the two eligible studies in the KSA [21, 22]. Neither of these studies was based on nationally representative samples. Both studies included adolescents only, and in both studies prevalence of obesity was much higher in boys than girls.

\section{Kuwait}

Table 5 summarises the 8 eligible studies from Kuwait. A number of the eligible studies were not based on representative samples, were not very recent, and had relatively small samples. The most informative of the data sources from Kuwait was the large and recent nationally representative survey from 2016 [23]. In this survey there was clear evidence of increasing prevalence of obesity with increasing age, and by adolescence one-quarter to one third of participants were obese according to the WHO definition. Among the other 7 eligible studies from Kuwait (Table 5), 3 reported comparisons between prevalence estimates according to the definition of obesity used. Prevalence estimates were generally lower with the IOTF definition than the CDC and WHO BMI-for-age definitions (Table 5). Four studies compared prevalence between the sexes, and in all cases found that prevalence was lower among girls than boys, though prevalence was still high among the girls (typically ranging between 20 and $45 \%$ of girls in the samples studied). 
Table 2 Study quality appraisal summary using the Joanna Briggs Institute, JBI, tool [15]

\begin{tabular}{|c|c|c|c|c|c|c|c|c|c|c|c|}
\hline Criteria-Paper & $\begin{array}{l}\text { AlBlooshi, } \\
2016[18]\end{array}$ & $\begin{array}{l}\text { AlJunaibi, } \\
2013[20]\end{array}$ & $\begin{array}{l}\text { Musaiger, } \\
2012[19]\end{array}$ & $\begin{array}{l}\text { Al-Hazzaa, } \\
2014 \text { [21] }\end{array}$ & $\begin{array}{l}\text { Musaiger, } \\
2016[22]\end{array}$ & $\begin{array}{l}\text { Al-Awadhi, } \\
2013[2]\end{array}$ & $\begin{array}{l}\text { Al-Haifi, } \\
2013[5]\end{array}$ & $\begin{array}{l}\text { Alrashidi, } \\
2015 \text { [26] }\end{array}$ & $\begin{array}{l}\text { El-Ghaziri, } \\
2011[27]\end{array}$ & $\begin{array}{l}\text { Elkum, } \\
2016 \\
{[28]}\end{array}$ & $\begin{array}{l}\mathrm{KNSS}_{,}^{\mathrm{a}} \\
2016 \\
{[29]}\end{array}$ \\
\hline $\begin{array}{l}\text { 1. Sampling frame } \\
\text { appropriate? }\end{array}$ & No & No & No & No & No & No & No & No & No & No & No \\
\hline 2. Sample appropriate? & Yes & Yes & Yes & Yes & Yes & Yes & Yes & Yes & Yes & Yes & Unclear \\
\hline 3. Sample size adequate? & Unclear & No & Yes & Yes & Yes & Unclear & Unclear & Unclear & Unclear & No & Yes \\
\hline $\begin{array}{l}\text { 4. Subjects \& settings } \\
\text { described? }\end{array}$ & Yes & Yes & No & Yes & Yes & Yes & Yes & Yes & Yes & Yes & No \\
\hline $\begin{array}{l}\text { 5. Analysis conducted to } \\
\text { ensure coverage? }\end{array}$ & No & No & No & No & No & Yes & Unclear & No & No & No & No \\
\hline $\begin{array}{l}\text { 6. Valid methods used to } \\
\text { define obesity? }\end{array}$ & Yes & Yes & Yes & Yes & Yes & Yes & Yes & Yes & Yes & Yes & Yes \\
\hline $\begin{array}{l}\text { 7. Obesity defined in same } \\
\text { way for all subjects? }\end{array}$ & Yes & Yes & Yes & Yes & Yes & Yes & Yes & Yes & Yes & Yes & Yes \\
\hline $\begin{array}{l}\text { 8. Appropriate analysis? } \\
\text { (numerator, denominator, } \\
\%, \mathrm{Cl} \text { ) }\end{array}$ & No & Yes & No & No & No & Yes & No & No & Yes & No & No \\
\hline $\begin{array}{l}\text { 9. Response rate } \\
\text { adequate/dealt with? }\end{array}$ & No & Yes & No & No & No & Yes & No & No & No & No & No \\
\hline Total/9 & 4 & 5 & 5 & 5 & 5 & 7 & 4 & 4 & 5 & 4 & 3 \\
\hline
\end{tabular}

${ }^{a}$ Kuwait Nutrition Surveillance System

\section{Discussion}

This systematic review showed that evidence on the prevalence of obesity among school age children and adolescents in the GCC states is limited. Only one nationally representative survey was identified, and only $3 / 6$ GCC states had any eligible data from the past 11 years, with multiple gaps in the evidence (e.g. for certain age groups) and weaknesses in the evidence (e.g. reliance on non-representative samples, lack of national surveys). More extensive and higher quality surveillance of obesity among school age children and adolescents in the GCC is required in future if the GCC states are to address the obesity epidemic effectively [7]. Regular high quality surveillance is essential to assess the scale of the obesity problem, to identify trends and inequalities, to drive obesity prevention and control measures, and to assess the impact of policy measures aimed at obesity prevention and control [7].

Despite limitations in the evidence base on obesity prevalence in the GCC nations noted above, some trends were apparent from the 11 eligible studies. First, the prevalence of obesity according to BMI-for-age was very high. For example, prevalence of obesity in UAE according to the WHO definition exceeded one third of the sample in the secondary school-age participants, and increased with increasing age. One-quarter to one third of participants were obese according to the WHO definition in the Kuwaiti national survey. Moreover, BMI-for-age substantially underestimates the prevalence of obesity (excessive fatness) in children [12, 13] so 'true' prevalence of obesity in these studies in the GCC would have been even higher if this bias arising from use of the BMI had been accounted for. None of the eligible studies or surveys acknowledged that their prevalence estimates were subject to this source of bias, or attempted to adjust for it. A large recent study [24] across Africa found that the WHO-BMI-for-age definition of obesity only identified around one third of children with excessive body fatness measured by a reference method (Total Body Water). Second, in most of the eligible studies the prevalence of obesity was higher in boys than girls, suggesting that this is a real difference in susceptibility to paediatric obesity in the GCC states. It should be noted that prevalence of obesity among the girls would also be regarded as very high relative to other nations $[10,11]$. Third, the eligible studies and surveys which compared prevalence estimates by the different definitions based on BMI-for-age found consistently that prevalence was substantially lower when the IOTF definition of obesity was used compared to definitions based on the CDC or WHO, consistent with previous evidence [12].

There are no previous systematic reviews of the prevalence of child or adolescent obesity from the GCC, and so the results of the present study cannot be compared easily with other evidence. Comparisons of prevalence of obesity among children and adolescents in the GCC with those living in other countries is also difficult because of differences in the timing of the studies, differences in the definitions of obesity used, and whether or not obesity prevalence estimates (as distinct from overweight prevalence estimates, or prevalence of overweight and obesity combined) can be found in published studies. 
Table 3 Obesity Prevalence, UAE

\begin{tabular}{|c|c|c|c|c|c|c|c|c|}
\hline $\begin{array}{l}\text { Author and } \\
\text { Year }\end{array}$ & Sample Size and age (n) & $\begin{array}{l}\text { Data Collection } \\
\text { (Years) }\end{array}$ & $\begin{array}{l}\text { Definition of Obesity } \\
\text { Used }\end{array}$ & Obesity Preval & lence (\%) by & Definition & & $\begin{array}{l}\text { Comments on Obesity } \\
\text { Prevalence Estimates }\end{array}$ \\
\hline \multirow{7}{*}{$\begin{array}{l}\text { Al Blooshi } \\
\text { et al., 2016) [18] }\end{array}$} & \multirow{2}{*}{$\begin{array}{l}\text { 44,942 (Males and females) } \\
\text { age 3-18years }\end{array}$} & \multirow[t]{7}{*}{ 2013-2015 } & \multirow{7}{*}{$\begin{array}{l}\text { International Obesity Task } \\
\text { Force (IOTF), World Health } \\
\text { Organization } 2007 \text { (WHO), } \\
\text { and Centers for Disease } \\
\text { Control (CDC) }\end{array}$} & \multicolumn{4}{|c|}{ Prevalence estimates for the nationals only } & \multirow{5}{*}{$\begin{array}{l}\text { The sample was } \\
\text { apparently not } \\
\text { representative of } \\
\text { the UAE. } \\
\text { Cls given for prevalence } \\
\text { estimates: No }\end{array}$} \\
\hline & & & & Age & IOTF & WHO & $\mathrm{CDC}$ & \\
\hline & \multirow{3}{*}{$\begin{array}{l}\text { This study was conducted } \\
\text { in two phases; the first } \\
\text { phase was in 2013-2014 } \\
(n=15,532) \text { age } 4-12 \text { years. }\end{array}$} & & & $3-6$ & 5.2 & 11.2 & 7.4 & \\
\hline & & & & $7-10$ & 12.4 & 27.0 & 16.7 & \\
\hline & & & & $11-14$ & 18.9 & 37.5 & 24.3 & \\
\hline & \multirow{2}{*}{$\begin{array}{l}\text { The second phase was in } \\
2014-2015(n=29,410) \\
n=27,078 \text { nationals and } \\
2332 \text { non-nationals } \\
\text { age 3-18 years. }\end{array}$} & & & $15-18$ & 19.3 & 33.8 & 22.2 & Biases considered: No \\
\hline & & & & & & & & $\begin{array}{l}\text { Prevalence higher in boys } \\
\text { than girls and generally } \\
\text { higher in older than } \\
\text { younger individuals }\end{array}$ \\
\hline \multirow{5}{*}{$\begin{array}{l}\text { Musaiger et al., } \\
\text { 2012) [19] }\end{array}$} & \multirow{5}{*}{$\begin{array}{l}605 \text { adolescents aged } \\
\text { from } 15 \text { to } 18 \text { years } \\
\text { ( } n=262 \text { males, } \\
243 \text { females) }\end{array}$} & \multirow[t]{5}{*}{ 2010-2011 } & \multirow[t]{5}{*}{ IOTF and CDC } & SEX & IOTF & \multicolumn{2}{|c|}{$\mathrm{CDC}$} & \multirow{3}{*}{$\begin{array}{l}\text { The sample was } \\
\text { apparently not } \\
\text { representative of } \\
\text { the UAE. }\end{array}$} \\
\hline & & & & Male & 19.1 & \multicolumn{2}{|c|}{22.5} & \\
\hline & & & & Female & 6.6 & \multicolumn{2}{|c|}{7.0} & \\
\hline & & & & & & & & $\begin{array}{l}\text { Cls given for prevalence } \\
\text { estimates: No }\end{array}$ \\
\hline & & & & & & & & $\begin{array}{l}\text { Prevalence higher in boys } \\
\text { than girls }\end{array}$ \\
\hline \multirow{7}{*}{$\begin{array}{l}\text { Al Junaibi et } \\
\text { al } 2013 \text { [20] }\end{array}$} & \multirow{7}{*}{$\begin{array}{l}\text { 1541, aged } 6-19 \text { years } \\
(n=1770 \text { males, } n=770 \\
\text { females })\end{array}$} & \multirow{7}{*}{$\begin{array}{l}\text { January- } \\
\text { December } \\
2011\end{array}$} & \multirow[t]{7}{*}{ IOTF and CDC } & SEX & IOTF & \multirow{7}{*}{\multicolumn{2}{|c|}{$\begin{array}{c}\mathrm{CDC} \\
21.4 \\
18.1 \\
\end{array}$}} & \multirow{3}{*}{$\begin{array}{l}\text { The sample was } \\
\text { representative of Abu } \\
\text { Dhabi but not the } \\
\text { entire UAE. }\end{array}$} \\
\hline & & & & Male & - & & & \\
\hline & & & & Female & - & & & \\
\hline & & & & & & & & $\begin{array}{l}\text { Cls given for prevalence } \\
\text { estimates: No }\end{array}$ \\
\hline & & & & & & & & Biases considered: No \\
\hline & & & & & & & & $\begin{array}{l}\text { The authors used IOTF to } \\
\text { define obesity prevalence } \\
\text { but data using IOTF } \\
\text { not shown. }\end{array}$ \\
\hline & & & & & & & & $\begin{array}{l}\text { Prevalence higher in older } \\
\text { individuals and slightly } \\
\text { higher in boys than girls }\end{array}$ \\
\hline
\end{tabular}

Table 4 Obesity Prevalence, Kingdom of Saudi Arabia

\begin{tabular}{|c|c|c|c|c|c|c|c|}
\hline \multirow{3}{*}{$\begin{array}{l}\text { Author and year } \\
\text { Al-Hazzaa et al., } \\
\text { 2014) [21] }\end{array}$} & \multirow{3}{*}{$\begin{array}{l}\text { Sample size }(n) \text { and } \\
\text { age of sample } \\
2908 \text { ( } n=1401 \text { males, } \\
n=1507 \text { females) } \\
\text { aged } 14 \text { to } 19 \text { years }\end{array}$} & \multirow{3}{*}{$\begin{array}{l}\text { Data collection } \\
\text { (Years) }\end{array}$} & \multirow{3}{*}{$\begin{array}{l}\text { Definition of } \\
\text { obesity used } \\
\text { IOTF }\end{array}$} & \multicolumn{3}{|c|}{ Obesity prevalence by methods } & \multirow{2}{*}{$\begin{array}{l}\text { Comments on obesity } \\
\text { prevalence estimates } \\
\text { The sample was apparently }\end{array}$} \\
\hline & & & & \multirow{2}{*}{$\begin{array}{l}\text { SEX } \\
\text { Male }\end{array}$} & \multicolumn{2}{|c|}{ IOTF } & \\
\hline & & & & & \multicolumn{2}{|c|}{24.1} & Jeddah and Riyadh, but not \\
\hline & & & & Female & \multicolumn{2}{|c|}{14.0} & representative of KSA \\
\hline & & & & & & & $\begin{array}{l}\text { Cls given for prevalence } \\
\text { estimates: No }\end{array}$ \\
\hline & & & & & & & Biases considered: No \\
\hline & & & & & & & $\begin{array}{l}\text { Prevalence higher in boys } \\
\text { than girls }\end{array}$ \\
\hline \multirow{6}{*}{$\begin{array}{l}\text { Musaiger et al., } \\
\text { 2016) [22] }\end{array}$} & \multirow{6}{*}{$\begin{array}{l}968 \text { adolescents aged } \\
15-18 \text { years ( } n=518 \\
\text { males, } n=450 \text { females) }\end{array}$} & \multirow{6}{*}{ 2013-2014 } & \multirow[t]{6}{*}{ IOTF, WHO } & SEX & IOTF & WHO & \multirow{3}{*}{$\begin{array}{l}\text { The sample represents } \\
\text { Dammam city but was } \\
\text { apparently not representative } \\
\text { of KSA. }\end{array}$} \\
\hline & & & & Male & 24.3 & 35.5 & \\
\hline & & & & Female & 15.3 & 8.0 & \\
\hline & & & & & & & $\begin{array}{l}\text { Cls given for prevalence } \\
\text { estimates: No }\end{array}$ \\
\hline & & & & & & & Biases considered: No \\
\hline & & & & & & & $\begin{array}{l}\text { Prevalence higher in boys } \\
\text { than girls }\end{array}$ \\
\hline
\end{tabular}


Table 5 Obesity Prevalence, Kuwait

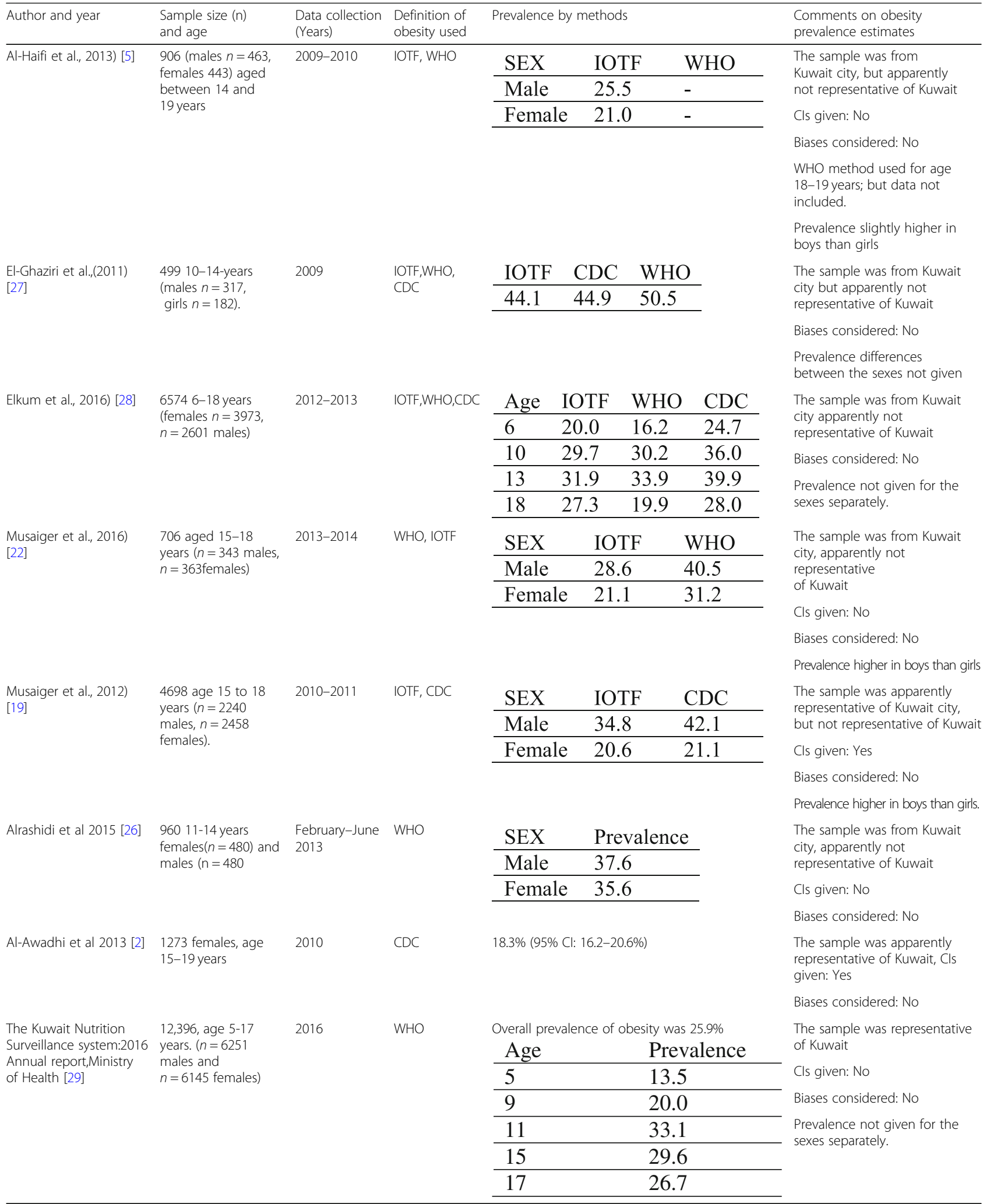


The present review found major limitations of obesity surveillance in the GCC, notably the apparent lack of any recent surveillance data from 3 of the 6 GCC countries, the availability of nationally representative sample data from only 1/6 GCC countries, the small sample sizes and scarcity of power calculations (and confidence intervals around prevalence estimates), and the fact that bias in the use of BMI-for-age to generate prevalence estimates was not considered by any of the 11 eligible studies/surveys. In addition, eligible study and survey response rates were often very low (under 50\%), and not reported in all of the eligible studies and surveys. It should be noted that many of the studies did not set out to obtain nationally representative samples, and estimating obesity prevalence was not a primary aim of all of the eligible studies. In addition, a checklist for guiding/assessing the quality of prevalence studies [15] only became available after many of the eligible studies were conducted. Future studies and surveys of child and adolescent obesity prevalence in the GCC states and elsewhere may find it useful to refer to the checklist for assessment of prevalence study quality used in the present study [15].

This review had a number of strengths. First, it focused on obesity-rather than overweight and obesity. While obesity and overweight are often combined somewhat casually in paediatric prevalence studies they are not equivalent clinically or biologically in children, as in adults: there is currently a very large body of consistent evidence of adverse health effects of obesity in childhood and adolescence [23, 25], but the adverse health impact of overweight in childhood and adolescence is much less clear at present. Second, the present review attempted to provide evidence of most relevance and highest quality, by including only relatively recent studies, and only those which used acceptable objective measures of obesity (rather than self-or parent reports), and by formal appraisal of study quality. The conduct of the present systematic review was also intended to follow best practice, by using the AMSTAR tool as a guide to the process, and reporting of the review followed PRISMA guidance. Finally, by making use of extensive expert contacts in all of the 6 GCC states, the probability that eligible studies and surveys (including grey literature) were not identified by the conventional literature search was reduced.

The present review also had a number of limitations. The number of eligible studies was relatively small due in part to our decision to exclude studies which collected data prior to 2007. The rationale for this is that we included only recent studies to provide up to date information, especially important given likely recent rapid increases in obesity prevalence in the GCC [1-4, $8,9]$. Including older studies would have increased the size of the evidence base, but also made it much less generalisable to contemporary GCC populations. The literature search was limited to English language for practical reasons, but any grey literature or other studies suggested by expert contacts in the GCC published in Arabic would also have been considered if identified. The first author is from Kuwait, which may have biased the grey literature searching towards Kuwaiti sources of evidence. However, author connections in relevant institutions in the rest of the GCC are good, and responses from those contacts were generally informative (Additional file 2). It therefore seems unlikely that useful sources of evidence from the other GCC states, such as recent nationally representative surveys, were missed.

\section{Conclusions}

There is a major gap in the literature on the childhood and adolescent obesity prevalence in the GCC states, with the exception of Kuwait. New research/surveys are needed for those countries in the GCC apparently not doing surveillance of child and adolescent obesity prevalence. For those countries where studies and surveys have been carried out, greater attention could be paid to the quality appraisal issues identified by the present review.

\section{Additional files}

Additional file 1: Table S1. Literature search terms in Medline. Search terms and syntax in Medline. (DOCX $14 \mathrm{~kb}$ )

Additional file 2: Table S2. GCC experts consulted on search findings and missing studies. Summary of experts contacted to check on search results, their affiliations, and their responses. (DOCX $14 \mathrm{~kb}$ )

Additional file 3: Table S3. List of excluded studies. Summary of fulltext screened studies excluded, with reasons for exclusion. (DOCX $26 \mathrm{~kb}$ )

\section{Abbreviations}

AMSTAR: Assessment of systematic reviews tool; BMl: Body mass index; CDC: Centers for Disease Control and Prevention; GCC: the Gulf Cooperation Council; IOTF: International Obesity Task Force; JBI: Joanna Briggs Institute; KSA: Kingdom of Saudi Arabia; UAE: United Arab Emirates; WHO: World Health Organization

\section{Acknowledgments \\ The authors would to like to acknowledge the support of the Ms. Sarah Kevill, specialist librarian, for help with the literature searching; Dr. Anne Martin for providing the prevalence study critical appraisal tool; all the academics who responded to emails requesting comments on the literature search, and requests for grey literature in the GCC states.}

\section{Funding}

Public Authority for Applied Education and Training, Kuwait; Kuwait Cultural Office; Scottish Funding council.

Availability of data and materials

Available from the corresponding author on reasonable request.

Authors' contributions

Initial study concept: JJR; Study design: both authors. Searching: HA. Eligibilty checking, Data extraction, Study quality assessment, both authors. Drafting of manuscript HA; Critical revisions of manuscript JJR. All authors read and approved the final version of the manuscript. 
Ethics approval and consent to participate

Not applicable.

\section{Consent for publication}

Not applicable.

\section{Competing interests}

The authors declare that they have no competing interests.

\section{Publisher's Note}

Springer Nature remains neutral with regard to jurisdictional claims in published maps and institutional affiliations.

Received: 28 February 2018 Accepted: 12 December 2018

Published online: 08 January 2019

\section{References}

1. Abdul-Rasoul MM. Obesity in children and adolescents in gulf countries: facts and solutions. Advances en Diabetología. 2012;28(3):64-9.

2. Al-Awadhi N, Al-Kandari N, Al-Hasan T, AlMurjan D, Ali S, Al-Taiar A. Age at menarche and its relationship to body mass index among adolescent girls in Kuwait. BMC Public Health. 2013:13(1):29.

3. Hammad SS, Berry DC. The child obesity epidemic in Saudi Arabia: a review of the literature. J Transcult Nurs. 2016:28:505-15.

4. Boodai SA, Reilly JJ. Health related quality of life of obese adolescents in Kuwait. BMC Pediatr. 2013:13:105

5. Al-Haifi AR, Al-Fayez MA, Al-Athari Bl, Al-Ajmi FA, Allafi AR, Al-Hazzaa HM, Musaiger AO. Relative contribution of physical activity, sedentary behaviors, and dietary habits to the prevalence of obesity among Kuwaiti adolescents. Food Nutr Bull. 2013;34(1):6-13.

6. Ng SW, Zaghloul S, Ali HI, Harrison G, Popkin BM. The prevalence and trends of overweight, obesity and nutrition-related non-communicable diseases in the Arabian Gulf States. Obes Rev. 2011;12(1):1-13.

7. Report of the Commission on Ending Childhood Obesity Implementation Plan. WHO/NMH/PND/ECHO/17.1, WHO 2017]. http://apps.who.int/iris/ bitstream/handle/10665/259349/WHO-NMH-PND-ECHO-17.1-eng.pdf; jsessionid=69FE14197C363C78E5E9C969AE9A576D? sequence $=1$.

8. Alshaikh MK, Filippidis FT, Al-Omar HA, Rawaf S, Majeed A, Salmasi A-M. The ticking time bomb in lifestyle-related diseases among women in the Gulf cooperation council countries; review of systematic reviews. BMC Public Health. 2017;17(1):536

9. Al-Refaee FA, Al-Qattan SA, Jaber SM, Al-Mutairi AA, Al-Dhafiri SS, Nassar MF. The rising tide of overweight among Kuwaiti children: study from Al-Adan hospital, Kuwait. Med Princ Pract. 2013;22(6):600-2.

10. Abarca-Gómez L, Abdeen ZA, Hamid ZA, Abu-Rmeileh NM, Acosta-Cazares B, Acuin C, Adams RJ, Aekplakorn W, Afsana K, Aguilar-Salinas CA. Worldwide trends in body-mass index, underweight, overweight, and obesity from 1975 to 2016: a pooled analysis of 2416 population-based measurement studies in children, adolescents, and adults. Lancet. 2017; 390(10113):2627-42.

11. The Global Burden of Disease Collaborators. Health effects of overweight and obesity in 195 countries over 25 years. N Engl J Med. 2017;377(1):13-27.

12. Reilly JJ, Kelly J, Wilson DC. Accuracy of simple clinical and epidemiological definitions of childhood obesity: systematic review and evidence appraisal. Obes Rev. 2010;11(9):645-55.

13. Javed A, Jumean M, Murad MH, Okorodudu D, Kumar S, Somers VK, Sochor O, Lopez-Jimenez F. Diagnostic performance of body mass index to identify obesity as defined by body adiposity in children and adolescents: a systematic review and meta-analysis. Pediatr Obes. 2015;10(3):234-44.

14. Moher D, Liberati A, Tetzlaff J, Altman DG. The PG: preferred reporting items for systematic reviews and meta-analyses: the PRISMA statement. PLOS Med. 2009:6(7):e1000097.

15. Joanna Briggs Institute. Quality appraisal tools. Checklist for prevalence studies.joannabriggs.org/research/critical-appraisal-tools.html. Accessed 4 Jan 2019.

16. Assessing the quality of systematic reviews AMSTAR checklist. https://www. bmj.com/content/358/bmj.j4008. Accessed 4 Jan 2019.

17. Reilly JJ. Descriptive epidemiology and health consequences of childhood obesity. Best Pract Res Clin Endocrinol Metab. 2005;19(3):327-41.
18. AlBlooshi A, Shaban S, AlTunaiji M, Fares N, AlShehhi L, AlShehhi H, AlMazrouei A, Souid AK. Increasing obesity rates in school children in United Arab Emirates. Obes Sci Pract. 2016;2(2):196-202.

19. Musaiger AO, Al-Mannai M, Tayyem R, Al-Lalla O, Ali EY, Kalam F, Benhamed MM, Saghir S, Halahleh I, Djoudi Z, et al. Prevalence of overweight and obesity among adolescents in seven Arab countries: cross-cultural study. J Obes. 2012;2012:981390

20. Al Junaibi A, Abdulle A, Sabri S, Hag-Ali M, Nagelkerke N. The prevalence and potential determinants of obesity among school children and adolescents in Abu Dhabi, United Arab Emirates. Int J Obes. 2013;37(1):68-74.

21. Al-Hazzaa HM, Abahussain NA, Al-Sobayel HI, Qahwaji DM, Alsulaiman NA Musaiger AO. Prevalence of overweight, obesity, and abdominal obesity among urban Saudi adolescents: gender and regional variations. J Health Pop Nutr. 2014;32(4):634-45.

22. Musaiger AO, Al-Mannai M, Al-Haifi AR, Nabag F, Elati J, Abahussain N, Tayyem R, Jalambo M, Benhamad M, Al-Mufty B. Prevalence of overweight and obesity among adolescents in eight Arab countries: comparison between two international standards (ARABEAT-2). Nutr Hosp. 2016;33(5):567.

23. Reilly JJ, Kelnar CJ, DW Alexander B, Hacking ZCMD, Stewart ML, Methven E Health consequences of obesity. Arch Dis Child. 2003;88:748-52.

24. Diouf A, Adom T, Aouidet A, El Hamdouchi A, Joonas NI, Loechl CU, Leyna GH, Mbithe D, Moleah T, Monyeki A, Nashandi H, Somda S, Reilly JJ. Body mass index versus deuterium dilution for establishing childhood obesity prevalence across 8 African countries. Bull WHO. 2018;96:772-81.

25. Reilly JJ, Kelly J. Long-term impact of childhood obesity on adult morbidity and premature mortality: systematic review. Int J Obes. 2011:35:891-8.

26. Al Rashidi M, Shahwan-Akl L, James J, Jones L. Contributing factors to childhood overweight and obesity in Kuwait. Int J Health Sci. 2015;3(1):133-55.

27. El-Ghaziri M, Boodai S, Young D, Reilly JJ. Impact of using national V. international definitions of underweight, overweight and obesity: an example from Kuwait. Public Health Nutr. 2011;14(11):2074-8.

28. Elkum N, Al-Arouj M, Sharifi M, Shaltout A, Bennakhi A. Prevalence of childhood obesity in the state of Kuwait. Pediatr Obes. 2016;11(6):e30-4.

29. Kuwait Nutrition Survey: Ministry of Health (Kuwait). Annual Report 2016. https://www.moh.gov.kw/Renderers/ShowPdf.ashx?ld=62b5708c-d2fa-45a5b677-c02632ac76a7

Ready to submit your research? Choose BMC and benefit from:

- fast, convenient online submission

- thorough peer review by experienced researchers in your field

- rapid publication on acceptance

- support for research data, including large and complex data types

- gold Open Access which fosters wider collaboration and increased citations

- maximum visibility for your research: over $100 \mathrm{M}$ website views per year

At $\mathrm{BMC}$, research is always in progress.

Learn more biomedcentral.com/submissions 